\title{
THE IMPORTANCE OF PSYCHOLOGICAL TESTING IN PREDICTING THE EFFECTIVENESS OF LUMBAR SPINE SURGERY
}

\author{
A IMPORTÂNCIA DO TESTE PSICOLÓGICO NA PREVISÃO DA EFICÁCIA DA CIRURGIA \\ DA COLUNA LOMBAR
}

\author{
LA IMPORTANCIA DE LAS PRUEBAS PSICOLÓGICAS EN LA PREDICCIÓN DE LA \\ EFECTIVIDAD DE LA CIRUGÍA DE LA COLUMNA LUMBAR
}

Aleksandr V. Krutko ${ }^{1}$, Olga N. Leonova ${ }^{1}$, Eugene A. Cherepanov ${ }^{1}$

1. Novosibirsk Research Institute of Traumatology and Orthopaedics (NRITO) n.a. Ya.L. Tsivyan, Novosibirsk, Russia.

\begin{abstract}
Objective: The result of treatment of patients with degenerative disc diseases is partly determined by the psychological characteristics of the patients. The aim of this study was to examine the correlations between the psychological scales scores in patients with degenerative lumbar disc diseases and the effectiveness of surgical treatment. Methods: The efficacy of the operation and patients' satisfaction were compared with the preoperative psychological characteristics, according to the questionnaires and scales (BBQ Symonds, Zung Scale, $F A B Q, P C I, B B Q$ Catastrophization). Results: In patients with neurogenic intermittent claudication syndrome without significant pain, the operative treatment depended significantly on the value of the BBQ Symonds scale $(p=0.016)$. In patients with severe radicular pain in the lower extremity, the effectiveness of the operation depended significantly on the value of the subscale "protection" of the PCl questionnaire $(p=0.04)$, the ODI index filled out before the operation $(p=0.0)$. In patients with lumbar syndrome, the effectiveness of operation depended significantly on the value of the PCl questionnaire as a whole $(p=0.042)$ and its subscores "rest" $(p=0.028)$, the index of the Oswestry filled out before the operation $(p=0.035)$. Conclusion: The effectiveness of the operation of degenerative lumbar disc diseases is associated with the results of preoperative psychological testing. It has been established that the BBQ Symonds scale, PCI protection and rest subscales, and the ODI questionnaire are the most significant; these psychological scales have the power to predict the effectiveness of surgical treatment. Level of Evidence II; Therapeutic Study - Investigating the Results of Treatment.
\end{abstract}

Keywords: Intervertebral disc degeneration; Catastrophizing; Pain, Postoperative.

\section{RESUMO}

Objetivo: O resultado no tratamento de pacientes com doenças degenerativas do disco é parcialmente determinado pelas características psicológicas dos pacientes. O objetivo do estudo foi examinar as correlações entre as escalas de índice psicológico em pacientes com doenças degenerativas do disco lombar e a eficácia do tratamento cirúrgico. Métodos: A eficácia da operação e a satisfação dos pacientes foram comparadas com as características psicológicas pré-operatórias, de acordo com os questionários e escalas (BBQ Symods, Zung Scale, $F A B Q, P C l$, Catastrofización de BBQ ). Resultados: Em pacientes com a síndrome de claudicação neurogênica intermitente sem dor significativa, o tratamento cirúrgico dependeu significativamente do valor da escala BBQ Symods $(p=0,016)$. Em pacientes com dor radicular grave no membro inferior, a eficácia da operação dependeu significativamente do valor da "proteção" da subescala do questionário de ICP $(p=0,04)$, preenchido antes da operação pelo índice ODI $(p=0,0)$. Nos pacientes com síndrome lombar, a eficácia da operação dependia significativamente do valor do questionário $\mathrm{PCl}$ como um todo $(p=0,042)$ e seu subscore "repouso" $(p=0,028)$ e o índice do Oswestry preenchido antes da operação $(p=0,035)$. Conclusão: A efetividade do funcionamento das doenças degenerativas do disco lombar está associada aos resultados dos testes psicológicos pré-operatórios. Foi estabelecido que a escala BBQ Symods, subescalas de proteção e descanso de $\mathrm{PCl}$ e o questionário de $\mathrm{ODI}$ são mais significativos; essas escalas psicológicas têm poder preditivo em relação à eficácia do tratamento cirúrgico. Nível de Evidência II; Estudo Terapêutico - Investigação dos resultados do tratamento.

Descritores: Degeneração do disco intervertebral; Catastrófização; Dor pós-operatória.

\section{RESUMEN}

Objetivo: El resultado del tratamiento de pacientes con enfermedades degenerativas del disco está parcialmente determinado por las características psicológicas de los pacientes. El objetivo del estudio fue examinar las correlaciones entre las escalas de índice psicológico en pacientes con enfermedades degenerativas del disco lumbar y la efectividad del tratamiento quirúrgico. Métodos: Se comparó la eficacia de la operación y la satisfacción de los pacientes con las características psicológicas preoperatorias según los cuestionarios y escalas (BBQ Symonds, Zung Scale, FABQ, PCl, Catastrofización de BBQ). Resultados: En pacientes con síndrome de claudicación neurogénica intermitente sin dolor significativo, el tratamiento quirúrgico dependió significativamente del valor de la escala BBQ Symonds $(p=0,016)$. En pacientes con dolor radicular severo en la extremidad inferior, la efectividad de la operación dependió significativamente del valor de la subescala "protección" del cuestionario PCI $(p=0,04)$, el índice ODI llenado antes de la operación $(p=0,0)$. En pacientes con síndrome lumbar, la efectividad de la operación dependió significativamente del valor del cuestionario $P C l$ como un todo $(p=0,042)$ y sus subcategorías "reposo" ( $p=0,028)$, el índice de Oswestry llenado antes de la operación $(p=0,035)$. Conclusión: La efectividad de la operación 
de las enfermedades degenerativas del disco lumbar se asocia con los resultados de las pruebas psicológicas preoperatorias. Se ha establecido que la escala de BBQ Symonds, las subescalas de protección y reposo PCl y el cuestionario ODI son los más significativos; estas escalas psicológicas tienen poder predictivo en relación con la efectividad del tratamiento quirúrgico. Nivel de Evidencia II; Estudio Terapéutico - Investigación de los resultados del tratamiento.

Descriptores: Degeneración del disco intervertebral; Catastrofizácion; Dolor posoperatorio.

\section{INTRODUCTION}

Degenerative diseases of the spine are one of the most common groups of pathologies of the musculoskeletal system. Their prevalence in the general population is around $25 \%$ and increases to $45 \%$ in individuals over 60 years of age. ${ }^{1,2}$ This nosology is characterized by chronic pain in the back or leg, and is often accompanied by persistent disability

Progression of pain, or chronic pain syndrome, the development of a neurological deficit, or failure of conservative treatment, may be factors that require surgical intervention. Even though spinal interventions have demonstrated surgical efficacy, the clinical outcomes of the surgeries range from 35 to $75 \%$ improvement, depending on the type of surgery perfomed performed, ${ }^{3-7}$ with up to $23 \%$ incidence of repeated surgeries. ${ }^{8}$ Up to $40 \%$ of patients note that the pain continues after the surgical treatment, albeit with lower intensity. ${ }^{9-11}$ These results indicate that the efficiency of treatment of patients with degenerative diseases of the spine is determined solely by the completeness of surgical treatment. There is increasing evidence that the observed variability in outcomes of spinal surgeries may be partially attributed to the preoperative psychological characteristics of patients in their study Adogwa and Carr et $\mathrm{al}^{12}$ demostrated demonstrated that preoperative screening of psychological status enables the identification of patients at risk of unfavorable outcomes of surgery; the baseline level of psychological predisposition was useful in predicting poor clinical outcomes after surgery.

The individual psychological characteristics of patients that affect the outcome of back pain and its treatment efficacy have now been established. Sinikallio et al. noted that favorable outcomes of treatment were recorded in patients with normal mood and without signs of depression, while depressive symptoms strongly influenced the ability of patients to accept the optimal treatment outcome..$^{13}$ Patients with high levels of depression, anxiety and fear avoidance often have unsatisfactory surgical outcomes and rarely return to work after the surgery. ${ }^{14-17} \mathrm{~A}$ group of other authors, based on their own research, concluded that high levels of anxiety and depression alone do not define unfavorable outcomes of surgical treatment for degenerative diseases of the spine. ${ }^{18}$ Archer et al. ${ }^{19}$ proved that fear of physical activity, overcoming difficulties, positive attitudes and depression individually and independently correlate with chronic back pain and subsequent disability, and also reduce physical activity after surgery. ${ }^{20,21}$

According to a group of researchers, psychological screening and appropriate therapy for the disorders identified can improve the results of surgical treatment. ${ }^{22}$ However, patients' satisfaction with surgery is directly correlated with the level of preoperative depression, regardless of the type of surgical intervention performed. ${ }^{23}$

There are currently many questionnaires and scales that allow reliable evaluation of patients' psychological characteristics. The most common ones are the scales that determine the patient's level of anxiety and the presence of depressive symptoms (Zung's scale, Hospital Anxiety and Depression Scale, questionnaires showing the level and avoidance of physical activity, the patients' ability to work (Fear Avoidance Beliefs Questionnaire, FABQ), Pain Coping Index (PCI), Oswestry questionnaire, Tampa scale of kinesiophobia, as well as some scales that assess patients' fears, attitudes and beliefs about their disease and the possibility of recovery (Back Beliefs Questionnaire (BBQ), Misbeliefs questionnaire, Catastrophization Scale). There are also psychological questionnaires that help to determine the subjective effectiveness of the treatment and patients' satisfaction (ODI change,
Likert's scale). Their application in practical medicine is necessary to assess the patient's satisfaction with the treatment and potentially predict the effectiveness of the treatment.

Published studies on the subject are based on various hypotheses and use various scales and questionnaires. Therefore, current practice lacks a standardized protocol for detecting psychological disorders that can have significant effect on the results of surgical treatment. A universal system for assessing the psychological state of patients with degenerative diseases of the spine already at the preoperative stage will help to predict the effectiveness of surgical treatment.

The aim of our study was to examine the relationships between psychological scores of patients with degenerative diseases of the spine and their satisfaction with subsequent surgical intervention. It was also important to identify psychological scales that have the greatest predicative force in different degenerative diseases of the spine.

\section{METHODS}

We conducted a prospective study of the effect of patients' psychological characteristics and personal beliefs on the outcomes of surgical treatment of degenerative diseases of the spine.

The study included 150 patients from the Novosibirsk Neurosurgical Unit No.2 of Novosibirsk NIITO who underwent surgical treatment for osteochondrosis of the lumbar spine. Patients with radicular pain syndrome and/or neurological deficits were included in the study. All patients underwent surgical treatment in the form of decompressive or decompressive-stabilizing surgeries. The patients were divided into three groups, based on the key syndrome. The first group consisted of patients with neurogenic intermittent claudication without severe pain syndrome in any area. The second group consisted of patients with predominant radicular pain syndrome without pronounced neurologic deficit. The third group consisted of patients with predominant lumbar syndrome also without marked neurological disorders.

The inclusion criteria were: over 18 years of age on the day of enrollment; planned surgical treatment for degenerative lumbar spine disorder; and a high likelihood of the patient remaining under a doctor's supervision and being available for a telephone interview 1 year after the surgery. The exclusion criteria were: the presence of concomitant pathology, which could cause back pain (malignant neoplasm, rheumatoid diseases, osteoporosis, fractures of the vertebral bodies); long-term use of corticosteroids; and patient's reluctance to adhere to recommendations in the postoperative period.

All patients underwent radiation diagnostics at the preoperative stage to confirm the substrate of the underlying disease, as well as a general clinical examination, and examination by specialists in related fields, if necessary

Psychological tests using questionnaires were employed to assess the personal attitudes of the patients towards their disease, and their general condition. This psychological testing was performed prior to the surgery to identify relationships between baseline psychological characteristics and the outcome of surgical treatment.

The study was approved by the local ethics committee under protocol no. 258, 11/12/2015. All patients provided written informed consent in accordance with the Declaration of Helsinki, which included their consent for the use of their data in the analyses and in the presentation of the results. The researcher received written informed consent from every potential participant in the study. 


\section{Data collection}

Demographic parameters were recorded for each patient on enrollment into the study: sex, age, clinical diagnosis, type of planned surgical intervention. The study did not interfere with the patients' treatment plans. The study included patients who were scheduled to undergo surgical intervention for pain and/or neurological deficits caused by degenerative diseases of the lumbar spine.

The psychological testing was performed at the preoperative stage, one day before the surgical intervention and the baseline testing included seven questionnaires.

The Back Beliefs Questionnaire (BBQ Symonds) describes the patient's beliefs about their current disease, prognosis, and possibility of recovery. Fear of intensifying the pain leads to avoidance of physical activity, which, in turn, leads to chronic pain and decreased ability to work. The evaluation was carried out using a questionnaire with 14 items, with responses on a scale of "do not agree" to "agree".

The Zung scale is based on analytical study of depression symptoms and assesses both psychological and physiological symptoms of depression in a patient. The respondents answer each question according to the extent to which it applied to them during the past week. There are types of answers in this questionnaire. The result is calculated in points and then a qualitative score is determined based on the sum of points, from "no depression" to "severe depression".

Waddell's Fear-Avoidance Beliefs Questionnaire (FABQ) is used to determine the degree of fear of pain and its impact on the patient's performance in two critical areas: "work" and "physical activity". The evaluation is performed by calculating points over 21 items. The higher the total score, the greater the degree of the patient's fear of pain during movements.

The Pain Coping Inventory $(\mathrm{PCl})$ is used to determine how people cope with back pain. The score is calculated across 8 scales ("Guarding", "Resting", "Asking for Assistance", "Relaxation", "Coping", "Task Persistence", "Social Support", "Exercises") and two main types of adaptation: "Active" and "Passive".

The Catastrophization Scale (BBQ Catastrophization) is used to assess catastrophic thinking associated with pain. The questionnaire consists of 13 questions that describe different thoughts and feelings that patients can experience in connection with pain. The patients were asked to evaluate their feelings on a scale from zero ("none") to four ("I think about it all the time"). The maximum score describes feelings of despair and helplessness.

Oswestry Disability Index (ODI) is an assessment of the degree of disability. The questionnaire contains 10 questions, each containing six possible responses ranging from zero to five. The total value is converted to a scale of 0 to 100 . According to studies, the Oswestry questionnaire is recommended by the World Health Organization to assess treatment effectiveness. The ODI is focused on physical activity, not on the psychological circumstances of pain syndrome.

The second round of psychological testing was conducted in the early postoperative period, when the patients were discharged for outpatient care, and consisted of filling in the Oswestry questionnaire.

The final psychological testing was conducted by a telephone interview one year after the surgery to evaluate its effectiveness and determine the patients' satisfaction. The patients completed the Oswestry questionnaire and the Likert scale.

The Likert scale shows patients' subjective satisfaction with the surgical treatment: from "absolutely dissatisfied" to "absolutely satisfied".

To assess the effectiveness of the surgical treatment, two Oswestry questionnaire scores were compared: before the surgery and one year after the surgery (ODI change). As recommended by the authors of the Oswestry questionnaire, changes of 10 points or more were considered clinically significant. Using this criterion, changes of 10 points or more towards the lower score were considered a sign of improvement, changes in either direction by less than 10 points were considered a lack of effect, and an increase in the Oswestry scale score of 10 points or more was considered a sign of worsening.

\section{RESULTS}

\section{Baseline characteristics}

Three groups of patients were formed over the course of the study. The first group consisted of patients with neurogenic intermittent claudication without severe pain syndrome in any area. This syndrome was caused by stenosis of the vertebral canal in the lumbar spine. This group included 19 patients (12 women and seven men) with a mean age of $57.95 \pm 7.08$ years (Group 1). The second group consisted of patients with pronounced pain syndrome in the lower extremity due to radiculopathy caused by a herniated disc in the lumbar spine. This group included 85 patients (44 women and 41 men) with a mean age of $45.22 \pm 12.98$ years (Group 2). The third group included patients with predominant back pain without pronounced neurologic deficit, which corresponded to functional incompetence of the lumbar spine. The group included 26 patients (10 women and 16 men) with a mean age of $48.54 \pm$ 10.71 years. (Group 3)

These groups were comparable in terms of sex, with no significant differences between them. (Table 1)

Patients in the first group were significantly older than patients in the second and third groups $(p<0.05)$. There were no significant differences between patients' ages in the second and third groups.

The patients underwent appropriate surgical treatment based on the established clinical diagnosis. The patients of the first group, who suffered from neurogenic intermittent claudication due to stenosis of the vertebral canal of the lumbar spine, underwent stabilizing operations. The patients from the second group, whose leading syndrome was radiculopathy due to a herniated disc in the lumbar spine, underwent decompressive or decompressive-stabilizing operations. The patients of the third group, suffering from low back pain as a manifestation of the functional incompetence of the lumbar spine, underwent stabilizing operations.

Comparative analysis of the psychological questionnaires scores (Table 2) in the three study groups, did not reveal significant pre-operative differences between the groups as measured by Symonds Catastrophization Scale, Zung scale, physical activity subscale of the Wadell's Fear-Avoidance Beliefs Questionnaire (FABQ), general scale of Pain Coping Index, general Back Beliefs Scale, and Oswestry scale (in all the cases, $\mathrm{p}>0.05$ ).

Based on the Zung scale scores, only a small proportion of patients in all groups experienced mild depression (up to $7.69 \%$ in the third group); most of the subjects had no depression.

Significant differences were observed between the first and second group $(p<0.05)$ according to the "work" subscale of Waddell's Fear-Avoidance Belief Questionnaire (FABQ).

Although the overall score on the Pain Coping Index did not reveal any differences between the groups, significant differences were observed in subscale comparison; there was significant difference between the first and second group $(p<0.05)$ on the "Resting" subscale.

There were significant differences between the first and second group $(p<0.05)$ in the Catastrophization Scale (BBQ).

Therefore, Group 1 is characterized as being older, and there are significant differences in the following psychological scales: "work" subscale of Fear-Avoidance Beliefs Questionnaire (compared to groups 2 and 3), "Resting" subscale of Pain Coping Index (compared to group 2), Catastrophization scale (compared to group 2). There were no significant differences between the second and third group at the preoperative stage.

Table 1. Characteristics of groups of patients by sex and age.

\begin{tabular}{c|c|c|c|c|c|c}
\hline Name & G0 & G1 & G2 & p.01 & p.02 & p.12 \\
\hline Sex : F & $12[63.16 \%]$ & $44[51.76 \%]$ & $10[38.46 \%]$ & \multirow{2}{*}{0.518} & 0.182 & 0.335 \\
\hline Sex : M & $7[36.84 \%]$ & $41[48.24 \%]$ & $16[61.54 \%]$ & & & \\
\hline Age, $M \pm m$ & $57.95 \pm 7.08$ & $45.22 \pm 12.98$ & $48.54 \pm 10.71$ & 0 & 0.001 & 0.196 \\
\hline
\end{tabular}


Table 2. General baseline characteristic of patients according to the psychological questionnaires, $M \pm m$, medians (the first quantile: the third quantile).

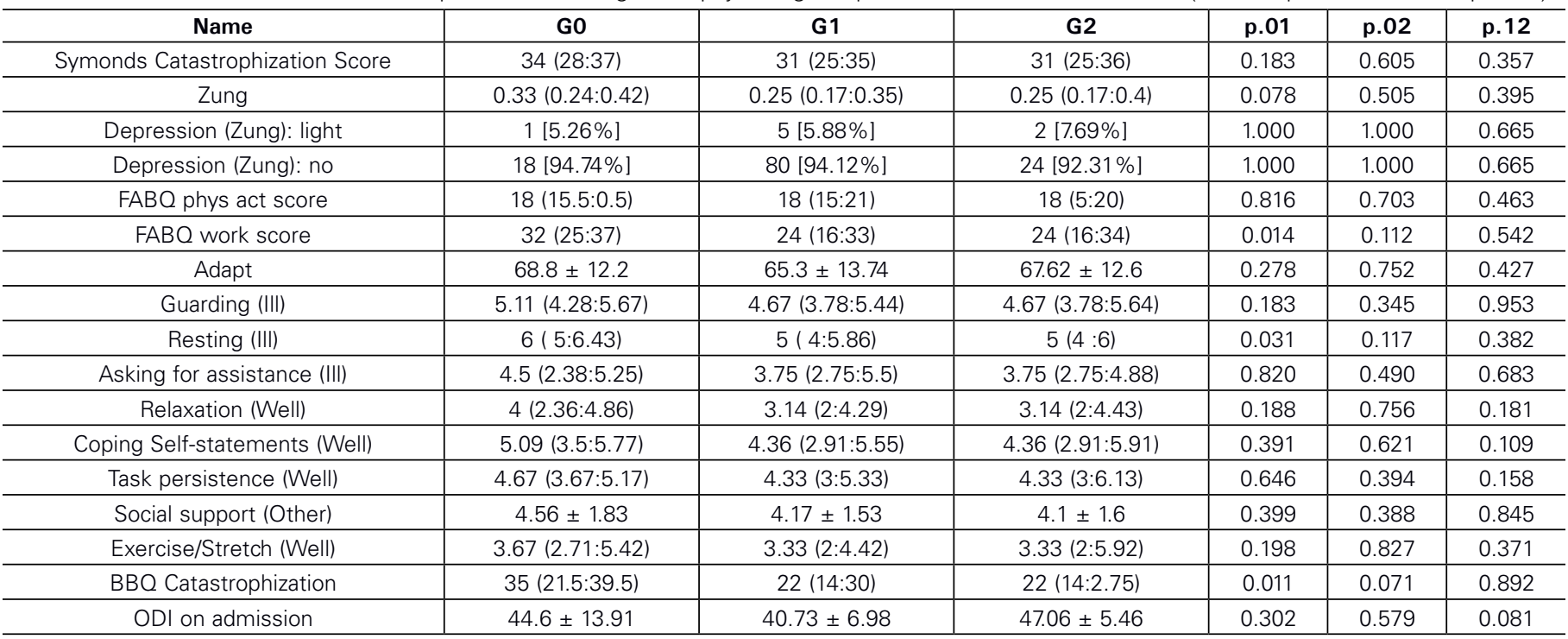

\section{Efficacy of surgery}

The patients completed the Oswestry questionnaire again upon discharge from inpatient care, enabling evaluation of the dynamics of the pain syndrome and the results of surgical treatment in the early postoperative period. The Oswestry "after surgery" score in patients of the second group was found to be significantly lower than the corresponding index in patients of the third group $(p<0.05)$. (Table 3 )

To assess the long-term outcomes of surgical treatment, the Oswestry questionnaire was completed one year after the surgery, and the patients also assessed their satisfaction using the Likert scale. (Table 4)

The Oswestry "in 1 year" score decreased in all three groups compared to baseline; for the patients of the second group, this index was significantly lower than for those of the first and third groups $(p<0.05)$.

The ODI change is the difference between the Oswestry index "on admission" and "1 year after the surgery", and determines the effectiveness of the treatment performed. Based on the value of this parameter, a positive effect of surgical treatment was observed in all three study groups, as measured by a decrease in the score of more than 10 points. There were no significant differences between the groups ( $p>0.05)$

Based on the Likert scale, the patients of all three groups were "very satisfied" with the results of the surgery. However, significant differences were observed between the results for groups 2 and $3(p<0.05)$.

Thus, the patients from the second group are characterized as having higher physical activity "after surgery" (ODI after surgery) compared to patients of the third group as well as "one year later" (ODI after one year) compared to patients of the first and third groups. In addition, the patients of the second group were more satisfied with the treatment compared to those of the third group.

Table 3. Values of the Oswestry index after the surgery, $\mathrm{M} \pm \mathrm{m}$.

\begin{tabular}{c|c|c|c|c|c|c}
\hline Name & G0 & G1 & G2 & p.01 & p.02 & p.12 \\
\hline $\begin{array}{c}\text { ODI after } \\
\text { surgery }\end{array}$ & $36.84 \pm 14$ & $31.16 \pm 14.54$ & $38.44 \pm 15.08$ & 0.124 & 0.716 & 0.036 \\
\hline
\end{tabular}

Table 4. Dynamics of ODI values 1 year later and the Likert scale, $M \pm m$, medians (the first quantile: the third quantile).

\begin{tabular}{c|c|c|c|c|c|c}
\hline Name & $\mathbf{G 0}$ & $\mathbf{G 1}$ & $\mathbf{G 2}$ & $\mathbf{p . 0 1}$ & $\mathbf{p . 0 2}$ & $\mathbf{p . 1 2}$ \\
\hline $\begin{array}{c}\text { ODI after } \\
\text { 1 year }\end{array}$ & $\begin{array}{c}28.89 \\
(16.89: 33.33)\end{array}$ & $12(2: 26)$ & $12(2: 40)$ & 0.007 & 0.662 & 0.012 \\
\hline ODI change & $-16.89 \pm 8.91$ & $-23.99 \pm 1.31$ & $-19.64 \pm 1.13$ & 0.159 & 0.649 & 0.364 \\
\hline $\begin{array}{c}\text { Likert } \\
\text { subjective }\end{array}$ & $2(1: 3)$ & $2(1: 3)$ & $2(1: 2)$ & 0.592 & 0.145 & 0.020 \\
\hline
\end{tabular}

\section{The relationship between the psychological scales and the outcome}

Given that the ODI change and the Likert scale demonstrated the effectiveness of surgical treatment and patients' satisfaction, we attempted to identify the relationship between these parameters and the demographic and psychological characteristics, using regression analysis.

It has been established that the effectiveness of surgical treatment and satisfaction with its outcome do not depend on the sex and age of a patient ( $p>0.05$ )

It has been shown that ODI change significantly depended on the "Guarding" subscale score of the Pain Coping Index questionnaire and the Oswestry questionnaire score, completed before the surgery $(p<0.05)$

It has been established that the ODI change in the first group (in patients without pain syndrome with neurogenic intermittent claudication) depended significantly on the value of the Symonds Catastrophization Scale ( $p<0.05)$.

It has been shown that ODI change in the second group (in patients with radiculopathy) depended significantly on the "Guarding" subscale score of the Pain Coping Index questionnaire and the Oswestry questionnaire score, completed before the surgery $(p<0.05)$.

It has been shown that ODI change in the third group (in patients with low back pain) depended significantly on the overall score on Pain Coping Index and its "Resting" subscale and the Oswestry questionnaire score, completed before the surgery $(p<0.05)$. In this group of patients, the Likert score (satisfaction with the treatment) depended significantly on "Passive" subscale score of Back Beliefs Questionnaire $(p<0.05)$.

The patients without pain syndrome (Group 1) are characterized by predominant fears about the disease, its prognosis and treatment options to a greater degree (according to Symonds Catastrophization scores).

\section{DISCUSSION}

According to the results of the study, the effectiveness of surgical treatment of osteochondrosis does not depend on the patient's demographic parameters (sex and age), while satisfaction with the treatment does not depend on the patient's demographic and psychological characteristics. The effectiveness of surgical treatment is significantly associated with the severity of changes in a patient's psychological state, as identified by the psychological questionnaires completed before the surgery (Symonds Catastrophization scale, "Guarding" and "Resting" subscales of the Pain Coping Index, and the Oswestry questionnaire index completed before surgery).

To date, several studies have been conducted to assess the 
risks of surgical treatment of patients with degenerative diseases of the spine and predict their outcomes. Great attention is given to psychological characteristics of patients as a parameter contributing to the effectiveness of surgical treatment and patient satisfaction with its outcome. Preoperative assessment of the patients' psychological characteristics, by filling out questionnaires and scales, allows us to identify factors that have predicative effect on the result of surgical treatment.

The effectiveness of surgical treatment is estimated by a change in the Oswestry index, ${ }^{23,24}$ reduction of pain syndrome as measured by the VAS scale, and changes in the parameters of other psychological scales (Catastrophization scale, Pain Coping Index, etc.). ${ }^{25-27}$ However, only the Oswestry index has recommendations for interpreting changes in the index, which is necessary to evaluate the effectiveness of treatment. ${ }^{28,29}$ According to the literature, the scales determining anxiety and depression are of the greatest importance. Kaisorn L. Chaichana et al. showed that the Zung scale enables the likelihood of clinical recovery to be better predicted in patients after decompressive surgery. ${ }^{30}$ According to Owoicho Adogwa et al., the Zung scale score is an independent predictor of the outcome of surgical treatment. ${ }^{23}$ However, in our study, the Zung scale score did not show significant correlation with the efficacy of surgical treatment; most subjects did not have depression, only $7.69 \%$ of patients with lumbar disorders had mild depression, and there were no significant correlation with the efficacy of the surgery.

Among numerous questionnaires assessing the physical activity of patients with osteochondrosis and their adaptation to pain, our study identified the Catastrophization scale, the Pain Coping Index (PCl), and the Oswestry questionnaire as those of the greatest importance.

Many studies have demonstrated a correlation between the patient's physical and psychological state. Great attention should be paid to models describing the patient's behavior when coping with the pain. The way a person copes with pain characterizes the degree of their adaptation to unfavorable factors in general. ${ }^{31,32}$ It has been shown that an exaggerated negative reaction to expected or actual pain, as measured by the Catastrophization scale, correlates with surgical outcomes. ${ }^{33,34}$ We have shown that in patients with neurogenic intermittent claudication, the effectiveness of surgical treatment depends on the Catastrophization scale score. This indicates that the more worried the patient is about their current state of health, prognosis and possibilities of recovery, the less effective the treatment will be.

Models such as "Resting", "Guarding" and "Coping" are characteristic of poor adaptation to pain. ${ }^{35,36}$ According to Misterska $E$ et al., "Guarding" subscale of the $\mathrm{PCl}$ is closely correlated with the severity of radicular pain syndrome. ${ }^{37}$ A number of researchers note the correlation between the Catastrophization Scale $(\mathrm{PCl})$ and the ODI score, before the surgery and three years after surgery. ${ }^{38} \mathrm{In}$ our study, patients with radicular pain syndrome typically followed the "Guarding" model and a significant correlation was established between this subscale and the effectiveness of surgical treatment. Patients with low back pain typically employed the "Resting" adaptation model, and the score on this subscale was closely correlated with the effectiveness of the surgery.

According to the literature, the Oswestry questionnaire is closely correlated with the level of physical activity, severity of pain, ${ }^{28,29}$ and treatment satisfaction. ${ }^{39}$ According to our data, the effectiveness of the surgery in patients with severe pain syndrome depends significantly on the Oswestry index before the surgery. The effectiveness of the treatment is defined by comparing the level of restrictions of physical activity due to pain in the back or leg, both before and after the surgery.

Patient satisfaction is measured by the Likert scale, which is a simple dichotomous scale ("yes" or "no"). ${ }^{25,40}$ The Likert scale is widely used in medical practice as a universal and simple tool for measuring this indicator. ${ }^{13,41}$ Our work shows that patients' satisfaction as measured by the Likert scale does not depend on sex and age, presence of pain, or type of surgical intervention, which is consistent with the data of other researchers. ${ }^{42,43}$ No significant correlation has been identified between patients' satisfaction and their psychological characteristics.

Based on the results of our study, we have identified the psychological scales that can help to assess personality traits that have significant impact on the effectiveness of ongoing surgical treatment. Given that the scales used to assess a patient's physical activity have the greatest prognostic value, this aspect should be studied in more detail. It is necessary to establish threshold values for psychological questionnaires for predicting the effectiveness of ongoing surgical treatment. Future results may require adjustments to the algorithm of preoperative management of patients with degenerative diseases of the spine.

\section{CONCLUSIONS}

According to the results of our study, the results of the psychological testing demonstrate significant correlation with the effectiveness of the surgical treatment of osteochondrosis and patients' satisfaction with the procedure. It has been established that the Symonds Catastrophization scale, "Guarding" and "Resting" subscales of the Pain Coping Index, "Avoidance" subscale of the Back Beliefs Questionnaire and the Oswestry questionnaire are of the greatest significance; these psychological scales have predictive power for the effectiveness of surgical treatment. These psychological questionnaires should be included in the preoperative examination plan for patients with degenerative diseases of the spine, which will enable the results of surgical treatment to be better predicted.

All authors declare no potential conflict of interest related to this article.

CONTRIBUTION OF THE AUTHORS: Each author made significant individual contributions to this manuscript. AVK (0000-0002-2570-3066) drafting of the entire research project, intellectual concept, revision and performing the surgeries, statistical analysis, review the manuscript. ONL (0000-0002-9916-3947)*: intellectual concept, gathering clinical data, analysis of the statistical data, writing the manuscript, and the literature search. EAC (0000-0001-6962-1401)*: intellectual concept, drafting of the entire research project, statistical analysis, writing the manuscript. *ORCID (Open Researcher and Contributor ID).

\section{REFERENCES}

1. Kalichman L, Kim DH, Li L, Guermazi A, Hunter DJ. Computed tomography-evaluated features of spinal degeneration: prevalence, intercorrelation, and association with selfreported low back pain. Spine J. 2010. 10(3):200-8.

2. Issack PS, Cunningham ME, Pumberger M, Hughes AP, Cammisa FP Jr. Degenerative lumbar spinal stenosis: evaluation and management. J Am Acad Orthop Surg. 2012. 20(8):527-35.

3. Turner JA, Ersek M, Herron L, Haselkorn J, Kent D, Ciol MA et al. Patient outcomes after lumbar spinal fusions. JAMA. 1992. 19:268(7):907-11.

4. Adogwa O, Parker SL, Shau DN, Mendenhall SK, Aaronson OS, Cheng JS et al. Preoperative Zung Depression Scale predicts outcome after revision lumbar surgery for adjacent segment disease, recurrent stenosis, and pseudarthrosis. Spine J. 2012, Vols. 12(3):179-85 5. Arts MP, Kols NI, Onderwater SM, Peul WC. Clinical outcome of instrumented fusion for the treatment of failed back surgery syndrome: a case series of 100 patients. Acta Neurochir (Wien). 2012. 154(7):1213-7.

6. Byvaltsev VA, Kalinin AA, Belykh EG, Sorokovikov VA, Shepelev VV. Optimization of segmental lumbar spine instability treatment using minimally invasive spinal fusion technique. Zh Vopr Neirokhir Im N N Burdenko. 2015. 79(3): 45-54.

7. Kalinin AA, Byvaltsev VA. Relationship between vertebral metric parameters and outcome of surgical treatment of degenerative spondylolisthesis with multilevel lumbar intervertebral disc lesions. Hirurgiâ pozvono nika. 12(4) (In Russ.), 2015, 56-62. 
8. Lurie JD, Tosteson TD, Tosteson A, Abdu WA, Zhao W, Morgan TS, et al. Long-term outcomes of lumbar spinal stenosis: eight-year results of the Spine Patient Outcomes Research Trial (SPORT). Spine (Phila Pa 1976). 2015, Vols. 40(2):63-76.

9. Atlas SJ, Keller RB, Wu YA, Deyo RA, Singer DE. Long-term outcomes of surgical and nonsurgical management of lumbar spinal stenosis: 8 to 10 year results from the maine lumbar spine study. Spine (Phila Pa 1976). 2005, Vols. 30(8):936-43.

10. Mannion AF, Denzler R, Dvorak J, Grob D. Five-year outcome of surgical decompression of the lumbar spine without fusion. Eur Spine J. Nov, 2010, Vols. 19(11):1883-91.

11. Weinstein JN, Tosteson TD, Lurie JD, Tosteson A, Blood E, Herkowitz H et al. Surgical versus nonoperative treatment for lumbar spinal stenosis four-year results of the Spine Patient Outcomes Research Trial. Spine (Phila Pa 1976). 2010, Vols. 35(14):1329-38.

12. Adogwa O, Carr K, Fatemi P, Verla T, Gazcon G, Gottfried O. et al. Psychosocial factors and surgical outcomes: are elderly depressed patients less satisfied with surgery? Spine (Phila Pa 1976). 2014, Vols. 39(19):1614-9.

13. Sinikallio S, Aalto T, Airaksinen O, Lehto SM, Kröger H, Viinamäki H. Depression is associated with a poorer outcome of lumbar spinal stenosis surgery: a two-year prospective follow-up study. Spine (Phila Pa 1976). 2011, Vols. 36(8):677-82

14. D'Angelo C, Mirijello A, Ferrulli A, Leggio L, Berardi A, Icolaro N. et al. Role of trait anxiety in persistent radicular pain after surgery for lumbar disc herniation: a 1-year longitudinal study. Neurosurgery. 2010 r., T. 67(2):265-71.

15. Pakarinen M, Vanhanen S, Sinikallio S, Aalto T, Lehto SM, Airaksinen O. et al. Depressive burden is associated with a poorer surgical outcome among lumbar spinal stenosis patients: a 5-year follow-up study. Spine J. 2014, 14(10):2392-6.

16. Miller JA, Derakhshan A, Lubelski D, Alvin MD, McGirt MJ, Benzel EC et al. The impact of preoperative depression on quality of life outcomes after lumbar surgery. Spine J. 2015, 15(1):58-64.

17. Nechanicka N, Barsa P, Harsa P. Psychosocial Factors in Patients Indicated for Lumbar Spinal Stenosis Surgery. J Neurol Surg A Cent Eur Neurosurg. 2016, 77(5):432-40.

18. Maratos EC, Trivedi R, Richards H, Seeley H, Laing RJ. Psychological distress does not compromise outcome in spinal surgery. Br J Neurosurg. 2012, 26(4):466-71.

19. Archer KR, Seebach CL, Mathis SL, Riley LH 3rd, Wegener ST. Early postoperative fear of movement predicts pain, disability, and physical health six months after spinal surgery for degenerative conditions. Spine J. 2014, 14(5):759-67.

20. Mannion AF, Elfering A, Staerkle R, Junge A, Grob D, Dvorak J et al. Predictors of multidimensional outcome after spinal surgery. Eur Spine J. 2007, 16(6):777-86.

21. Seebach CL, Kirkhart M, Lating JM, Wegener ST, Song Y, Riley LH 3rd et al. Examining the role of positive and negative affect in recovery from spine surgery. Pain. 2012, 153(3):518-25

22. Anderson JT, Haas AR, Percy R, Woods ST, Ahn UM, Ahn NU. Clinical depression is a strong predictor of poor lumbar fusion outcomes among workers' compensation subjects. Spine (Phila Pa 1976). 2015, 40(10):748-56.

23. Adogwa O, Parker SL, Shau DN, Mendenhall SK, Bydon A, Cheng JS et al. Preoperative Zung depression scale predicts patient satisfaction independent of the extent of improvement after revision lumbar surgery. Spine J. 2013, 13(5):501-6.

24. Murphy HA, Warnick E, McGintee R, Nicholson K, Hollern DA, Stawicki C et al. Which Domains of the ODI Best Predict Change in Physical Function in Patients after Surgery for Degenerative Lumbar Spondylolisthesis? Spine (Phila Pa 1976). 2017.

25. Havakeshian S, Mannion AF. Negative beliefs and psychological disturbance in spine surgery patients: a cause or consequence of a poor treatment outcome? Eur Spine J. 2013, 22(12):2827-3

26. Roitberg BZ, Thaci B, Auffinger B, Kaplan L, Shen J, Brown FD et al. Comparison between patient and surgeon perception of degenerative spine disease outcomes-a prospective blinded database study. Acta Neurochir (Wien). 2013, 155(5):757-64.

27. Urban-Baeza A, Zárate-Kalfópulos B, Romero-Vargas S, Obil-Chavarría C, Brenes-Rojas L, Reyes-Sánchez A. Influence of depression symptoms on patient expec- tations and clinical outcomes in the surgical management of spinal stenosis. $J$ Neurosurg Spine. 2015, 22(1):75-9.

28. Djurasovic M, Glassman SD, Dimar JR 2nd, Crawford CH 3rd, Bratcher KR, Carreon LY Changes in the Oswestry Disability Index that predict improvement after lumbar fusion. J Neurosurg Spine. 2012, 17(5):486-90.

29. Adogwa O, Elsamadicy AA, Han JL, Cheng J, Karikari I, Bagley CA. Do measures of surgical effectiveness at 1 year after lumbar spine surgery accurately predict 2-year outcomes? J Neurosurg Spine. 2016, 25(6):689-696.

30. Chaichana KL, Mukherjee D, Adogwa O, Cheng JS, McGirt MJ. Correlation of preoperative depression and somatic perception scales with postoperative disability and quality of life after lumbar discectomy. J Neurosurg Spine. 2011, 14(2):261-7.

31. Misterska E, Jankowski R, Głowacki M. Psychometric properties of the Polish language version of the chronic pain coping inventory-42 for patients treated surgically due to herniated lumbar discs and spondylotic changes. Med Sci Monit. 2014, 20:789-801.

32. Benaim C, Léger B, Vuistiner P, Luthi F. Validation of the French Version of the "Patterns of Activity Measure" in Patients with Chronic Musculoskeletal Pain. Pain Res Manag. 2017, 2017:6570394.

33. Kovacs FM, Seco J, Royuela A, Peña A, Muriel A and Network., Spanish Back Pain Research. The correlation between pain, catastrophizing, and disability in subacute and chronic low back pain: a study in the routine clinical practice of the Spanish National Health Service. Spine (Phila Pa 1976). 2011, 36(4):339-45

34. Cho S, Kim HY, Lee JH. Validation of the Korean version of the Pain Catastrophizing Scale in patients with chronic non-cancer pain. Qual Life Res. 2013 ..22(7):1767-72.

35. Heneweer $H$, van Woudenberg NJ, van Genderen F, Vanhees L, Wittink H. Measuring psychosocial variables in patients with (sub) acute low back pain complaints, at risk for chronicity: a validation study of the Acute Low Back Pain Screening Questionnaire-Dutch Language Version. Spine (Phila Pa 1976). 2010, 35(4):447-52.

36. Versteegh MM, Leunis A, Uyl-de Groot CA, Stolk EA. Condition-specific preference-based measures: benefit or burden? Value Health. 2012, 15(3):504-13

37. Misterska $E$, Jankowski R, Głowacki M. Chronic pain coping styles in patients with herniated lumbar discs and coexisting spondylotic changes treated surgically: Considering clinical pain characteristics, degenerative changes, disability, mood disturbances, and beliefs about pain control. Med Sci Monit. 2013, 19:1211-20.

38. Kim C, Harris JA, Muzumdar A, Khalil S, Sclafani JA, Raiszadeh K et al. The effect of anterior longitudinal ligament resection on lordosis correction during minimally invasive lateral lumbar interbody fusion: Biomechanical and radiographic feasibility of an integrated spacer/plate interbody reconstruction device. Clin Biomech (Bristol, Avon). 2017, 43:102-108

39. Chotai S, Devin CJ, Archer KR, Bydon M, McGirt MJ, Nian H et al. Effect of patients' functional status on satisfaction with outcomes 12 months after elective spine surgery for lumbar degenerative disease. Spine J. 2017, 17(12):1783-1793.

40. Johansson AC, Linton SJ, Rosenblad A, Bergkvist L, Nilsson O. A prospective study of cognitive behavioural factors as predictors of pain, disability and quality of life one year after lumbar disc surgery. Disabil Rehabil. 2010, 32(7):521-9.

41. Archer KR, Devin CJ, Vanston SW, KoyamaT, Phillips SE, George SZ et al. CognitiveBehavioral-Based PhysicalTherapy for Patients With Chronic Pain Undergoing Lumbar Spine Surgery: A Randomized Controlled Trial. J Pain. 2016, 17(1):76-89.

42. Chapman JR, Norvell DC, Hermsmeyer JT, Bransford RJ, DeVine J, McGirt MJ, Lee MJ. Evaluating common outcomes for measuring treatment success for chronic low back pain. Spine (Phila Pa 1976). 2011, 36(21 Suppl):S54-68

43. Donk RD, Verbeek ALM, Verhagen WIM, Groenewoud H, Hosman ATF, Bartels RHMA. Substantial clinical benefit for Neck Disability Index revisited: establishing the goal for treatment? Eur Spine J. 2017. 